\title{
Policing and Crime Act 2017: changes to pre-charge bail and the impact on digital forensic analysis
}

\author{
Graeme Horsman \\ School of Science, Engineering \& Design \\ Email: g.horsman@tees.ac.uk \\ Angela King \\ School of Social Sciences, Humanities \& Law \\ Email: a.king@tees.ac.uk \\ Teesside University \\ Middlesbrough \\ Tees Valley \\ TS1 3BX
}

\begin{abstract}
Following the enactment of the Police and Crime Act 2017, subsequent amendments to the Police and Criminal Evidence Act 1984 have seen a 'cap' placed on the length of time a suspect can be released on bail; a process commonly referred to as 'police bail' or 'pre-charge bail'. Whilst designed to instil consistency and certainty into bail processes to prevent individuals being subject to lengthy periods of regulation and uncertainty, it places additional pressures on forensic services. With a focus on digital forensics, examination of digital media is a complex and time consuming process, with existing backlogs well documented. The need for timely completion of investigations to adhere to pre-charge bail rules places additional stress on an already stretched service. This comment submission provides an initial analysis of new pre-charge bail regulations, assessing their impact on digital forensic services.
\end{abstract}

Keywords: Bail; Digital Forensics; Pre-charge bail; Police and Criminal Evidence Act 1984; Police and Crime Act 2017.

\section{Introduction}

Bail is a long established process of the criminal justice system, providing an option to temporarily release an individual from custody subject to future investigation or legal proceedings (Gov.uk, 2017a). Bail can be both 'pre' and 'post' charge, impacting an individual subject to such conditions in different ways. Following section 37 of the Police and Criminal Evidence Act 1984 (PACE), post-charge bail can occur where sufficient evidence exists in order to charge a suspect with an offence (Crown Prosecution Service, 2017). Bail conditions can be imposed upon the bailee following section 47 PACE, requiring them to attend court at a future date with repercussions for those who breach conditions. Pre-charge bail (sometimes referred to as 'police bail') provides the converse, where no charge occurs but further investigation or consultation is required, allowing an individual to continue with their normal life whilst potentially subject to bail terms (McGuinness, 2016). The cases of Paul Gambaccini and Freddy Starr provide insight into the use of long-term pre-charge bail times and subsequent criticisms of this process (McGuinness, 2016).

Prior to the changes by the 2017 Act, those subject to pre-charge bail may previously have faced an indefinite wait for police investigations to complete. Such a scenario has attracted the following dissenting comments from Home Secretary Amber Rudd.

"Pre-charge bail is a useful and necessary tool but in many cases it is being imposed on people for many months, or even years, without any judicial oversight - and that cannot be right." (Gov.uk, 2017b) 
Now, following the enactment of the Police and Crime Act 2017 (PACA), which came into force in April 2017, pre-charge bail must now be limited to 28 days (subject to extension request requirements). The new provisions under Part 4 (s.63) of the PACA have added to the existing rules under PACE, inserting s. 47ZA-47ZM to the original framework. Whilst this amendment provides an increased level of certainty in terms of length of proceedings to the suspect, its implementation places additional pressure on forensic investigatory services, particularly those involved with digital device analysis.

This submission provides a discussion of the pre-charge bail amendments, examining their potential impact upon digital forensic services.

\subsection{Pre-charge bail: An overview}

Pre-charge bail regulation changes in regards to length of time a person can remain 'on bail' now set out the following conditions.

- Following any initial detention, a 28-day length limit is imposed upon any subsequent pre-charge bail imposition (s.47ZB PACE).

- A superintendent maintains the ability to extend pre-charge bail to a total of 3 months (starting from initial pre-charge bail date, s.47ZD PACE).

- In some circumstances, an additional extension (beyond the powers of a superintendent) can be sought from the Magistrates Court, provided the requirements set out under either s.47ZF or s.47ZG PACE are satisfied.

Bail will be imposed under section 34 PACE, provided two conditions are met. First, a custody officer deems it necessary, for further investigation of any matter in connection with which the person was detained, or proceedings may be taken against the person. Second, bail must be authorised by an inspector or above. For an extension to pre-charge bail to be applicable, the statutory conditions under section 47ZC PACE need to be considered (College of Policing, 2017). The inclusion of the words 'necessary and proportionate suspicion' within this section ensure that the new provisions are consistent with the issue of 'reasonable grounds' found in respect of other powers under PACE (notably the powers to stop and search under s.1(3) and the powers of arrest under s.24). Moreover, these provisions ensure compatibility with the rights guaranteed by the European Convention on Human Rights and Fundamental Freedoms (1950) (ECHR), as determined by the Strasbourg Court in cases such as Gillan and Quinton v United Kingdom [2010] ECHR 28, which the Police, acting as a public authority, are legally required to protect (s.6 Human Rights Act 1998).

The Crown Prosecution Service (2017) have stated that 'bail decisions made by a Court can result in the deprivation or restriction of liberty for a substantial period of time'. It should be noted that despite deterring repeated and indefinite bailing, legislation did not wholly prohibit it (Bernard, 2016). The amendments to PACE, brought about via PACA are designed to safeguard bailees and arguably better protect their right to liberty, under Article 5 ECHR, ensuring greater consistency, which is a fundamental principle in any democracy, determined by the rule of law. Such sentiment is echoed by the Minister for Policing Brandon Lewis (Home Office, 2017).

"We needed to rebalance this system for the benefit of all concerned. Today's changes will bring an end to those long periods of bail without any independent oversight that we have seen in the past.

Police officers will keep on doing their crucial work. But now anyone on pre-charge bail will have their case reviewed regularly and independently. That's the right thing to do and I thank the police for their swift and efficient work in preparing for these new rules." 
The length of time which individuals spent on bail prior to recent amendments had led to serious concerns (Mckinnon, 2017; Siddorn, 2017), leading to pre-charge bails portrayal as 'a legal limbo, an assault on liberty and punishment without trial' (McGuinness, 2016). In 2014, over 70,000 individuals were reported to be subject to pre-charge bail and over 5,000 for at least six months (Green et al., 2014). In 2016, The College of Policing (2016b) reported that 'around 80,000 people will be on bail at any one time and that nearly a half of these cases will result in no charges being brought'. Whilst in decreasing pre-charge bail time, a greater sense of procedural certainty is provided to those subject to this process, however, in doing so, the pressure to complete necessary investigations in increased.

\section{Implications of time on investigations}

The College of Policing's (2016) study into the use of pre-charge bail found that the mean length of initial pre-charge bail for sampled cases was 46 days. $41 \%$ of cases involving violence or sex offences were bailed for over 28 days, and $9 \%$ of cases were initially pre-charge bailed for over 90 days (cases involving rape and sexual offences or drug offences). Hucklesby's (2013) investigation into pre-charge bail found that from around 14,000 pre-charge bail records analysed from two UK police forces, "just under half of all cases in which pre-charge bail was imposed ended in no further action. Suspects were bailed 'just in case' evidence came to light even when it was foreseeable that their cases would result in no further action'.

Further, it is reported that forensic analysis is one of the main factors in $60 \%$ of the cases where over 90 days are required for pre-charge bail (College of Policing, 2016; 2016b). In regards to bail, 'it should always be the investigative officer's objective to complete the investigation in the first period of detention wherever possible' (College of Policing, 2017). Whilst a valid statement, case management, work loading and resource issues may in reality hinder the success of achieving this goal. One area of particular concern surrounds digital forensic analysis services (College of Policing, 2016; 2016b), where the examination and interpretation of data stored on a seized digital device is needed before further decisions can be made. Digital Forensics backlogs have been widely reported for some time (BBC News, 2015; Scanlon, 2016; Lillis et al., 2016; BBC News, 2017), with delays of up to 5 months for computer-based investigations in Greater Manchester noted by MP Ann Coffey (Coffey, 2017). The College of Policing's pre-charge bail report identifies the following challenges posed by digital examination times.

'The most frequent type of forensic analysis given as a reason for bail was 'phone downloads', accounting for thirteen percent of all cases with a mean number of days bailed of 71 , ranging from 44 to 104 days across the forces in the sample. In cases bailed for over 90 days, thirty-three percent gave 'phone downloads' as a reason for bail. 'Computer interrogation' accounted for only three percent of cases $(n=517)$ it had the longest mean length of bail at 84 days, ranging from 57 to 128 days. Of the cases where 'computer interrogation' was given as a reason, sixty three percent of the cases related to rape or other sexual offences and ten percent related to fraud offences'(College of Policing, 2016, p.7-8).

Time is often impacted in digital investigations by three factors, notably complexity, volume of data and available resources.

Complexity:- It is difficult to define complexity in the context of digital investigations as it is a factor often impacted by existing knowledge and tools. Almost all digital data in need to investigation is complex, however if 'know-good' methodologies have been designed and verified, examination complexity and subsequent times may be reduced, where verification of results may be straight forward. Yet given the diversity of applications, software and devices in circulation, it is common for practitioners to face bespoke and undocumented scenarios, requiring the undertaking of primary research to fully understand content resident on a device and its impact on a given case. In this scenario, research and development can extend case-completion times extensively, where time is needed to ensure the accuracy and 
reliability of newly developed knowledge and techniques. The dynamic nature and pace of change within technology makes defining and adhering to a consistent timeframe for completing digital forensic investigations in line with pre-charge bail frameworks almost impossible. There will always be cases which can be processed in as little time as a day, and those which take significantly longer.

Volume:- Volume is a persistent challenge. As digital devices become more entangled in acts of crime, either directly or indirectly, practitioners are now facing increased workloads. Not only are more devices in need of investigation, each device typically maintains a greater level of internal storage. The task of processing larger volumes of data remains a topic of interest, and one still in need of a universal consistent solution (Horsman et al., 2014; Quick and Choo, 2014). As a result, the time restrictions of pre-charge bail are being applied to a moving target, one where feasibility remains an issue. Whilst time extensions are designed to negate such issues, the cumulative effect of incoming cases and time pressures may ultimately prove too great. The volume of data in need of investigation is arguably increasing year on year with more time required for its effective analysis. Yet placing a cap on the length of pre-charge bail (including extensions) may be counter-productive in terms of the production of thorough examination results.

Further, new bail regulations do not have a retrospective application (as required by A.7 ECHR) therefore those already subject to bail conditions prior to PACA may find their cases of lower priority whilst time contained ones are processed first.

Resources:- Resourcing issues continue to influence decision making and performance in the digital forensic field and link closely to the two aforementioned issues. In an ideal world, greater volumes of work lead to the acquisition of both additional equipment and manpower. Yet financial constraints and the somewhat fickle nature of incoming casework often means that many organisations may choose to stockpile and tackle existing work with existing assets, leading to delays and backlogs. Such an approach may be counterproductive to new pre-charge bail approaches. Resourcing issues are beginning to surface with recent failures in regards to digital evidence disclosures having attracted media attention (BBC News, 2018), with the National Police Chiefs' Council (2018) acknowledging that this is partially due to the increase in the investigatory demands placed upon those carrying out this work. Whilst effective disclosure procedures are necessary to ensure 'fairness and impartiality' in an investigation, this process takes time correctly implement, potentially slowing down an inquiry (National Police Chiefs' Council, 2018). Such considerations sit in contravention to the bail amendments which try to decrease case processing times.

\section{Potential consequences}

Titchener (2017) suggests that stricter bail time limits will lead to an increase in 'voluntary police interviews' where suspects are simply asked to attend a police station for interview as opposed to compelled. On completion, individuals are released without bail but informed of ongoing investigations. Zander (2017) suggests that the 'release of arrested persons without bail is plainly therefore intended to become normal, if not the norm, requiring a major culture change for the police'. Such approaches also have the potential to create the levels of uncertainty generated by previously uncapped bail procedures. Whereas those released on pre-charge bail have the comfort of knowing that an investigation must come to a close at a specific point, those released without bail but are subject to further enquiries do not have this luxury. Instead they are left with uncertainty (knowing that re-arrest can occur at any point) as to when they are no longer under scrutiny (College of Policing 2016b). Where a digital device is involved, practitioners may look to create a forensic image (essentially a clone of resident data) or extraction of its content and store it for later analysis when resources are available. This analysis may take some time and following the identification of potentially relevant information, a re-arrest may occur. Concerns over re-arrests following release without bail were issued by Liberty (2015) during consultation processes and in turn, the impact that such knowledge may have on the wellbeing of a suspect. Questions must be raised as to whether pre-charge bail regulations will also 
negatively impact workloads of those involved in the process (Bernard, 2016). If it remains likely that those on pre-charge bail will be subject to extensions, those required to examine and grant these may see an influx of additional requests. Whilst the underpinning motives behind a defined bail-time seem logical, the repeated use of extensions to combat this may simply lead to those who will still remain on bail, subject to the conditions and worries associated with uncertainty.

Enforcement of time conditions also risk compromising the robustness of a forensic investigation (Liberty, 2015). Bernard (2016) suggests that penalties applied to those carrying out investigations from which the results are the cause of delays, would lead to improved efficiency and a 'shake-up' of the overall process. Yet, it is difficult to justify rushing the scientific examination of data in criminal contexts given the potential consequences associated to any legal processes. Digital forensics already engages with triage processes, designed to speed up the identification of evidential data, but such techniques come with inherent risks and can rarely attribute the same level of confidence to finding in comparison to a device undertaking a full examination (Pollitt, 2013; Horsman, 2014). Imposing conditions on practitioners to produce results within restricted time frames risks in such conditions may lead to increased errors and compromise investigations in the long-term. A push to produce quicker results is likely to see a greater reliance on triage processes, leaving behind traditional detailed investigation processes.

Finally, the scenario where an individual is released with no bail, despite having committed an offence. Whilst forensic analysis will reveal evidence of this, the gap in time between release and subsequent analysis and re-arrest may be great. During this time, a suspect remains at large, subject to none of the bail conditions and scrutiny of those which may previously be subjected to pre-charge bail. Concerns are raised where a suspect knows they will be subject to re-arrest and proceeds to undertake a final crime spree. There remains a risk that those who have offended remain not only at large (as bailed suspects would also), but free from surveillance or knowledge of other law enforcement catchment areas, an issue expressed by the head of crime and criminal justice at the College of Policing, David Tucker (BBC News, 2016). Pre-charge bail is designed 'to offer protection to complainants or witnesses, to preserve evidence and to mitigate the risk of further criminality'(McGuinness, 2016). Yet now, if a preference for release without bail is made, such safeguards are no longer in place.

\section{Concluding thoughts}

The introduction of new pre-charge bail regulations brought about by PACA are designed to bring clarity to the bail process and protect those subject to it by preventing the position of lengthy uncertainty. Whilst arguably established timeframes provide a greater level of guidance, their impact on digital forensic analysis process is likely to be great. This form of forensic analysis is unpredictable in terms of defining how long it will take to complete an investigation. However, it is now being asked to produce results within a relatively rigid framework and practically, this is unlikely to work well. Further insight in the coming months as the discipline starts to witness the full impact of PACA will begin to reveal whether such bail amendments are a positive addition where digital evidence is involved.

\section{References}

BBC News (2015) 'Child abuse cases delayed by police backlog' Available at: http://www.bbc.co.uk/news/uk-34713745 (Accessed 20th October 2017)

BBC News (2016) 'Police bail restriction plans 'dangerous" Available at: http://www.bbc.co.uk/news/uk-37488494

BBC News (2017) 'Report shows computer delays in child grooming inquiries' Available at: http://www.bbc.co.uk/news/uk-england-manchester-39436827 (Accessed 20th October 2017) 
BBC News (2018) 'All current rape cases to be 'urgently' reviewed over disclosure fears' Available at: http://www.bbc.co.uk/news/uk-42841346 (Accessed 19th February 2018)

Bernard, Nick (2016) 'Pre-charge Bail' Available at:

https://www.criminallawandjustice.co.uk/comment/Pre-Charge-Bail (Accessed 20th October 2017)

Coffey, Ann (2017) 'Real Voices Are they being heard?' Available at: https://www.gmpcc.org.uk/wpcontent/uploads/2017/03/RV2-Are-They-Being-Heard3.pdf (Accessed 20th October 2017)

College of Policing (2016) 'Bail report Pre-charge bail - an exploratory study' Available at: http://www.college.police.uk/News/College-news/Documents/Bail report document 439E0816 2.pdf (Accessed 12th July 2017)

College of Policing (2016b) 'Pre-charge bail: The possible implications of research' Available at: http://www.college.police.uk/News/College-news/Documents/College of Policing Precharge Bail Briefing.pdf (Accessed 12th December 2017)

College of Policing (2017) 'Detention and custody: Response, arrest and detention' Available at: https://www.app.college.police.uk/app-content/detention-and-custody-2/response-arrest-anddetention/ (Accessed 12th July 2017)

Crown Prosecution Service (2017) 'Bail' http://www.cps.gov.uk/legal/a to c/bail/ (Accessed 12th July 2017)

European Convention on Human Rights and Fundamental Freedoms, 1950

Gillan and Quinton v United Kingdom [2010] ECHR 28 Available at :

http://www.bailii.org/eu/cases/ECHR/2010/28.html (Accessed 12th December 2017)

Gov.uk (2017a) 'Being charged with a crime' Available at:

http://www.legislation.gov.uk/ukpga/2017/3/part/4/chapter/1/enacted (Accessed 12th July 2017)

Gov.uk (2017b) '28 day pre-charge bail limit comes into force' Available at: https://www.gov.uk/government/news/28-day-pre-charge-bail-limit-comes-into-force (Accessed 12th July 2017)

Green, Damien., Nigel Evans, Eddy Shah, David Davis, Caroline Lucas, Baroness Butler-Sloss, Lord Black of Brentwood, Baroness Kennedy of The Shaws, Lord Paddick, Frances Cook, Lord Finkelstein, Dominic Raab, Janet Street Porter, John Hemming, Gavin Millar, Roy Greenslade, Jon Robins, Sir Edward Garnier, Renate Samson, Steven Barker, Matthew Elliott, Peter Tatchell, Peter Tatchell, Andy McNab, Baroness Jones of Moulsecoomb, Andrew Caplen, Milos Stankovic, Graham Stringer. (2014) 'The injustice of pre-charge police bail' Available at: http://www.telegraph.co.uk/comment/letters/11266386/The-injustice-of-pre-charge-police-bail.html

(Accessed 12th July 2017)

Horsman, G., Laing, C. and Vickers, P., 2014. A case-based reasoning method for locating evidence during digital forensic device triage. Decision Support Systems, 61, pp.69-78.

Hucklesby, Anthea (2013) 'Pre-charge bail: an investigation of its use in two police forces' Available at: http://www.law.leeds.ac.uk/assets/files/research/ccis/pre-charge-bail/Briefing-paper-Pre-charge-

Police-Bail.pdf (Accessed 12th October 2017) 
Human Rights Act 1998

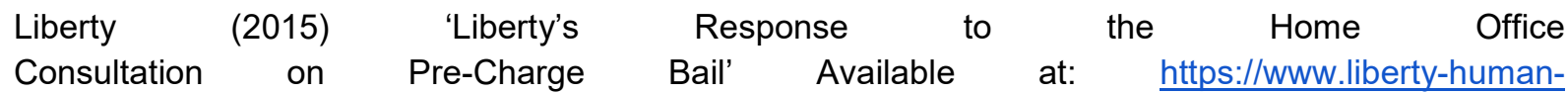
rights.org.uk/sites/default/files/Liberty $\% 27 \mathrm{~s} \% 20$ Response $\% 20$ to $\% 20$ the $\% 20$ Government $\% 27 \mathrm{~s} \% 20$ Pre -Charge\%20Bail\%20Consultation\%20\%28Feb\%202015\%29.pdf (Accessed 1st November 2017)

Lillis, D., Becker, B., O'Sullivan, T., Scanlon, M. "Current Challenges and Future Research Areas for Digital Forensic Investigation" The 11th ADSFL Conference on Digital Forensics, Security and Law (CDFSL 2016), Daytona Beach, Florida, USA, May 2016.

McGuinness, Terry (2016) 'Pre-charge bail' House of Commons Library Number 7469, 15 January 2016

Mckinnon, Lisa (2017) 'Police and Crime Act 2017 - does this really mean the end of lengthy pre-charge bail conditions?' Available at:http://www.byrneandpartners.com/blog/police-and-crime-act-2017--doesthis-really-mean-the-end-of-lengthy-pre-charge-bail-conditions (Accessed 12th July 2017)

National Police Chiefs' Council (2018) 'Police Chiefs' blog: CC Sara Thornton on Disclosure - February 2018' Available at: http://www.npcc.police.uk/ThePoliceChiefsBlog/PoliceChiefsblogCCSaraThorntononDisclosureFebrua ry.aspx (Accessed 19th February 2018)

Police and crime Act 2017

Police and Criminal Evidence Act 1994

Pollitt, M.M., 2013. Triage: a practical solution or admission of failure. Digital Investigation, 10(2), pp.8788.

Scanlon, M., 2016, August. Battling the digital forensic backlog through data deduplication. In Innovative Computing Technology (INTECH), 2016 Sixth International Conference on (pp. 10-14). IEEE.

Siddorn, Jennifer (2017) 'Police and Crime Act 2017 Police Station Training - Jennifer Siddorn' Available at: https://www.hja.net/wp-content/uploads/Police-and-Crime-Act-2017.pdf (Accessed 12th July 2017)

Titchener, Nick (2017) 'Are you "under investigation"? The changes to Police Bail' Available at: $\quad$ http://www.lawtonslaw.co.uk/resources/are-you-under-investigation-the-changes-topolice-bail/ (Accessed 12th July 2017)

Quick, D. and Choo, K.K.R., 2014. Impacts of increasing volume of digital forensic data: A survey and future research challenges. Digital Investigation, 11(4), pp.273-294.

Quick, D. and Choo, K.K.R., 2016. Big forensic data reduction: digital forensic images and electronic evidence. Cluster Computing, 19(2), pp.723-740.

Zander, Michael (2017) 'The Policing and Crime Act 2017' Available at: https://www.criminallawandjustice.co.uk/features/Policing-and-Crime-Act-2017 $\quad$ (Accessed: 1st November 2017) 